\title{
Toward Complete Sequence Flexibility of Nucleic Acid Base Analogue FRET
}

\author{
Moa S. Wranne, ${ }^{\dagger}$ Anders Foller Füchtbauer, ${ }^{\dagger}{ }^{\dagger}$ Blaise Dumat, ${ }^{\dagger, \# \odot ~ M a t t i a s ~ B o o d, ~}{ }^{\dagger}, \S^{\circ}$
} Afaf H. El-Sagheer, ${ }^{\|, \perp \odot}$ Tom Brown, ${ }^{\| \odot}$ Henrik Gradén, ${ }^{\S \odot}$ Morten Grøtli, ${ }^{\ddagger}$ and L. Marcus Wilhelmsson* ${ }^{* \dagger}$

${ }^{\dagger}$ Department of Chemistry and Chemical Engineering/Chemistry and Biochemistry, Chalmers University of Technology, Gothenburg S-41296, Sweden

${ }^{*}$ Department of Chemistry and Molecular Biology, University of Gothenburg, Gothenburg S-41296, Sweden

${ }^{\S}$ Cardiovascular and Metabolic Diseases, Innovative Medicines and Early Development, AstraZeneca, Mölndal S-43183, Sweden

"Chemistry Research Laboratory, Department of Chemistry, University of Oxford, Oxford OX1 3TA, United Kingdom

${ }^{\perp}$ Chemistry Branch, Faculty of Petroleum and Mining Engineering, Suez University, Suez 43721, Egypt

\section{Supporting Information}

\begin{abstract}
Förster resonance energy transfer (FRET) using fluorescent base analogues is a powerful means of obtaining high-resolution nucleic acid structure and dynamics information that favorably complements techniques such as NMR and X-ray crystallography. Here, we expand the basebase FRET repertoire with an adenine analogue FRET-pair. Phosphoramidite-protected quadracyclic 2'-deoxyadenosine analogues qAN1 (donor) and $\mathrm{qA}_{\text {nitro }}$ (acceptor) were synthesized and incorporated into DNA by a generic, reliable, and high-yielding route, and both constitute excellent adenine analogues. The donor, qAN1, has quantum yields reaching $21 \%$ and $11 \%$ in single- and double-strands, respectively. To

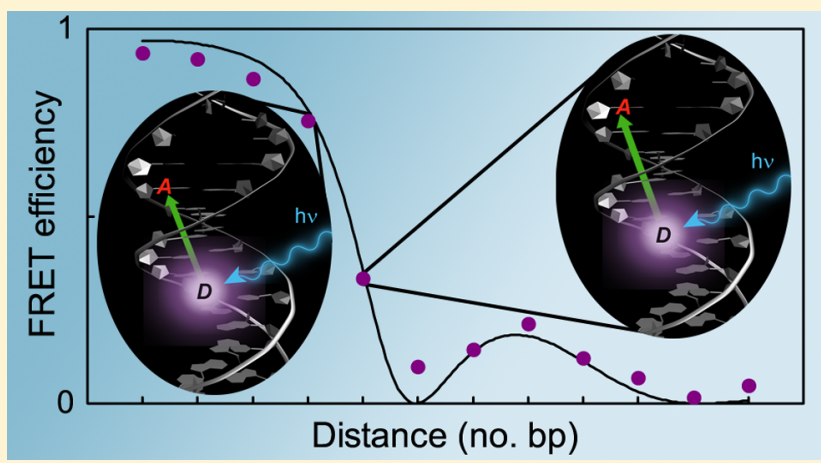
the best of our knowledge, this results in the highest average brightness of an adenine analogue inside DNA. Its potent emissive features overlap well with the absorption of $\mathrm{qA}_{\text {nitro }}$ and thus enable accurate FRET-measurements over more than one turn of B-DNA. As we have shown previously for our cytosine analogue FRET-pair, FRET between qAN1 and $\mathrm{qA}_{\text {nitro }}$ positioned at different base separations inside DNA results in efficiencies that are highly dependent on both distance and orientation. This facilitates significantly enhanced resolution in FRET structure determinations, demonstrated here in a study of conformational changes of DNA upon binding of the minor groove binder netropsin. Finally, we note that the donor and acceptor of our cytosine $\mathrm{FRET}$-pair, $\mathrm{tC}^{\mathrm{O}}$ and $\mathrm{tC}_{\text {nitro }}$, can be conveniently combined with the acceptor and donor of our current adenine pair, respectively. Consequently, our base analogues can now measure basebase FRET between 3 of the 10 possible base combinations and, through base-complementarity, between all sequence positions in a duplex.
\end{abstract}

\section{INTRODUCTION}

Fluorescence is a versatile and sensitive tool for studying a wide range of chemical, physical, and biological processes. With the scarcity of intrinsic emissive building blocks in biology, the development of fluorophores, such as fluorescent nucleobase and amino acid analogues as well as fluorescent proteins, is vital. ${ }^{1,2}$ Moreover, the wide variety of analytical methods available, ranging from standard steady-state to time-resolved and single-molecule emission as well as the 2014 Nobelawarded super-resolution microscopy techniques, ${ }^{3,4}$ has enabled high sensitivity and quality studies by taking advantage of the emissive properties of these fluorophores.

Förster resonance energy transfer (FRET) is one of the most significant, highly sensitive, and useful fluorescence techniques, and is often used to study structure and dynamics of biomacromolecular systems. ${ }^{5-8}$ Because of the strong distance dependence of the energy transfer efficiency (eq S5) between the donor and the acceptor, FRET is sometimes referred to as a spectroscopic ruler. ${ }^{9}$ Moreover, the efficiency of the energy transfer, through the Förster distance $\left(R_{0}\right.$, the distance where the energy transfer is $50 \%$ ), is also highly dependent on the relative orientation of the donor and acceptor transition dipole moments, and, hence, FRET is also an excellent spectroscopic protractor. Consequently, exact knowledge of the position and orientation of the donor and acceptor is essential in detailed FRET structure and dynamics investigations, except in a few cases where single molecule measurements are combined with molecular dynamics (MD) simulations, in an ingenious but elaborative way, to give detailed $3 \mathrm{D}$-structures of DNA. ${ }^{10}$

Received: May 3, 2017

Published: June 14, 2017 
Like the majority of biomolecules, DNA and RNA are virtually nonemissive and, thus, require fluorescence labeling either by external, for example, Cy-, Alexa-, and Atto-dyes, or by internal modifications, for example, fluorescent base analogues (FBAs). ${ }^{11-13}$ In general, an external modification has the advantage of being commercially available, bright, and photostable. ${ }^{13}$ However, the additional molecular mass and bulk as well as the general difficulty in predicting and determining its position, orientation, and dynamics relative to the nucleic acid system constitute major disadvantages that result in lower structural resolution, as well as restricting information on the dynamics of the system.

To avoid the uncertainties in position and orientation mentioned above, we have put significant effort into developing rotationally restricted internal fluorophores. This allows us to obtain high-resolution FRET by taking full advantage of the orientation dependence. ${ }^{5,6,14,15}$ We have previously reported on the first FBA FRET-pair that uses the tricyclic cytosine analogues $\mathrm{tC}^{\mathrm{O}}$ and $\mathrm{tC}_{\text {nitro }}$ as the donor and acceptor, respectively. ${ }^{16}$ While the vast majority of fluorescent base analogues are useful due to their high sensitivity to the surrounding microenvironment, ${ }^{11-13,17,18}$ the tricyclic cytosines $\mathrm{tC}^{\mathrm{O}}$ and $\mathrm{tC}$ are two rare examples of FBAs that are both bright ( $\Phi_{\mathrm{f}}=22 \%$ and $19 \%$, respectively) and virtually insensitive to the microenvironment inside duplex DNA. ${ }^{19,20}$ These unique characteristics are, in combination with the restricted motion of the tricyclic cytosines within duplexes, critical for FRETdistance measurements, and for the control and accuracy of $R_{0}$. Hence, they are of great value for detailed nucleic acid structural studies utilizing FRET. Consequently, the $\mathrm{tC}^{\mathrm{O}}-$ $\mathrm{tC}_{\text {nitro }}$ FRET-pair provides a unique opportunity to study the structure and dynamics of nucleic acids at high resolution. ${ }^{21}$ However, their use is limited to the cytosine bases positioned inside nucleic acids, which means that only one of the 10 possible FRET-pair combinations is covered. Therefore, our long-term aim is to expand our set of FBA FRET-probes to enable replacement of all of the natural nucleobases with FBAs that possess useful properties.

Here, we report on the synthesis and characterization of the FRET-donor qAN1, which we recently investigated as a monomer, $^{22}$ and the FRET-acceptor $\mathrm{qA}_{\text {nitro }}$ inside DNA (Chart 1). Moreover, we evaluate the properties of qAN1 and $\mathrm{qA}_{\text {nitro }}$ as adenine analogues and use the minor groove binder netropsin to demonstrate the use of our new FRET-pair in structural studies. Interestingly, we find not only that qAN1$\mathrm{qA}_{\text {nitro }}$ constitute an excellent adenine-adenine analogue FRET-pair, but, additionally, that they can be combined with the chromophores from our previously developed $\mathrm{tC}^{\mathrm{O}}-\mathrm{tC}_{\text {nitro }}$ FRET-pair. Consequently, our base analogues now cover 3

Chart 1. Structure of qA, qAN1 Base Paired with Thymine $(\mathrm{T})$, and $\mathrm{qA}_{\text {nitro }}{ }^{a}$

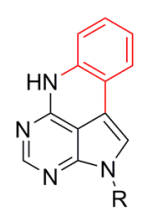

qA

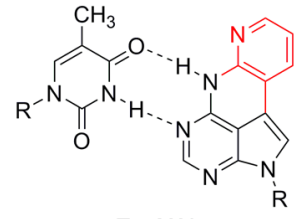

T-qAN1

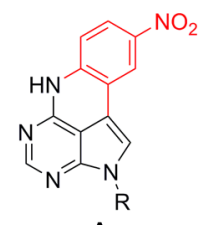

qA $A_{\text {nitro }}$
${ }^{a}$ Atoms of adenine (with N-7 replaced with C) and thymine are shown in black. $\mathrm{R}$ denotes the sugar-phosphate backbone.
$(\mathrm{C}-\mathrm{C}, \mathrm{A}-\mathrm{A}$, and $\mathrm{C}-\mathrm{A} / \mathrm{A}-\mathrm{C})$ of the 10 possible nucleobase combinations.

\section{RESULTS AND DISCUSSION}

In an effort to improve the brightness of the promising adenine analogue $\mathrm{qA}^{23}$ we recently investigated a series of $N^{9}$-ethylated model compounds, qAN1-4, where the outer benzene ring is replaced with a pyridine ring. ${ }^{22}$ Monomeric qAN1 (Chart 1) was shown to have an almost 3-fold increase in quantum yield $(18 \%)$ as well as a 5-fold increase in brightness as compared to $\mathrm{qA}$ and was therefore considered to be a promising FBA and FRET-donor candidate to incorporate into DNA. ${ }^{22}$ To enable energy transfer from qAN1 inside DNA, we also set out to develop an adenine FRET-acceptor using the established strategy of red-shifting the absorption via the introduction of a nitro-group ${ }^{16}$ to the $\mathrm{qA}$-chromophore.

Synthesis of Phosphoramidite Monomers of qAN1 and $\mathbf{q A}_{\text {nitro }}$. The phosphoramidite-protected quadracyclic 2 'deoxyadenosine analogues $\mathrm{qAN1}(\mathbf{1 a})$ and $\mathrm{qA}_{\text {nitro }}(\mathbf{1 b})$ were synthesized over 12 steps from 6-chloro-7-iodo-7-deazapurine (2) in $19.0 \%$ and $14.4 \%$ yield, respectively (Scheme 1 ). The quadracyclic scaffold was prepared before the $N$-glycosylation to give a more flexible synthetic route capable of accommodating variations in the substitution pattern on the quadracyclic scaffold. $^{23} N^{9}$-Protection of 2 with the less common tertbutyldimethylsilyloxymethyl (TBDMSOM) group $^{24-26}$ was achieved in excellent yield via a two-step procedure that represents a significant improvement of the original protocol. ${ }^{25}$ The resulting compound 3 was readily borylated with pinacolborane to furnish 4 in high yield (91\%). Compound 4 was used in Suzuki-Miyaura cross-coupling reactions with aryl halides, to furnish $\mathbf{5 a}$ and $\mathbf{5 b}$ in $86 \%$ and $95 \%$ yield, respectively.

The intramolecular ring-closing reaction to form $\mathbf{6 a}$ and $\mathbf{6 b}$ has been carried out for $N^{9}$-ethylated 5 a by TMS-activation followed by treatment with LiHMDS under microwave irradiation. $^{2,27}$ However, this approach failed for these $N^{9}$ TBDMSOM protected substrates, presumably due to the formation of a large amount of the inert doubly $N$-silylated material. Instead, $\mathbf{5 a}$ and $\mathbf{5 b}$ were activated by acetylation. Acetylation of $\mathbf{5 b}$ gave exclusively the monoacetylated derivative, which was ring-closed with LiHMDS in THF at $100{ }^{\circ} \mathrm{C}$ with microwave irradiation. Acetylation of 5a gave a mixture of nonacetylated, monoacetylated, and diacetylated material (approximately 0.1:1:1), which ring-closed readily with LiHMDS to form $\mathbf{6 a}$, suggesting that the diacetylated material is also a good substrate for this reaction.

To avoid interference from the nonparticipating amino group in the glycoside coupling, the secondary amine of $\mathbf{6 a}$ and $\mathbf{6 b}$ was Boc-protected using Boc anhydride and DMAP in THF, to afford $7 \mathbf{a}$ and $7 \mathbf{b}$ in excellent yield. The TBDMSOM protecting group was removed with tetrabutylammonium fluoride (TBAF) and ethylene diamine in THF to afford compounds $\mathbf{8 a}$ and $\mathbf{8 b}$ in near-quantitative yield. The $N$-glycosylation was performed using $\mathrm{NaH}$ in acetonitrile, followed by addition of Hoffer's $\alpha$ chlorosugar, 12 , $^{28}$ affording the $\beta$-anomers of nucleosides 9a and $9 \mathrm{~b}$ in $69 \%$ and $55 \%$ yield, respectively.

A global deprotection, using sodium methoxide in methanol at $50{ }^{\circ} \mathrm{C}$, gave the deprotected $\mathrm{qA}_{\text {nitro }}$ nucleoside, $10 \mathrm{~b}$, in nearquantitative yield. However, a similar treatment of $\mathbf{9 a}$ gave a complex mixture of products. Switching solvent to acetonitrile gave a much cleaner reaction and furnished the deprotected qAN1 nucleoside, 10a, in $81 \%$ yield. Compounds 10a and $10 \mathrm{~b}$ 
Scheme 1. Synthesis of the Phosphoramidite Monomers of qAN1 (1a) and $\mathrm{qA}_{\text {nitro }}$

(1b)

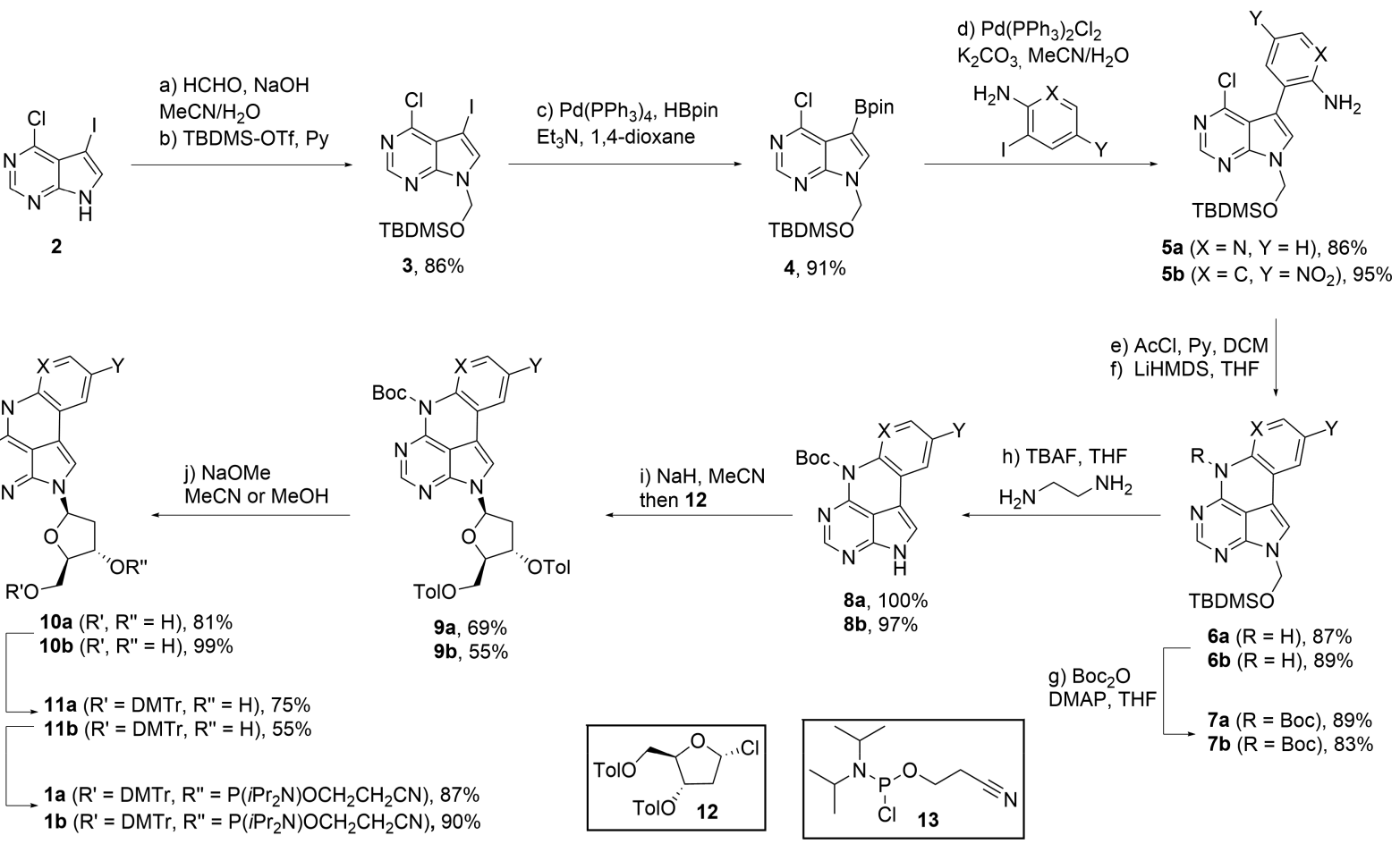

were DMTr-protected and converted to the phosphoramidite monomers of $\mathrm{qAN} 1$ and $\mathrm{qA}_{\text {nitro }}$ using standard procedures.

Incorporation of qAN1 into DNA Oligonucleotides. To study the effect of replacing adenine with qAN1 on DNA structure and stability as well as whether the photophysical properties of qAN1 are sensitive to neighboring bases, we synthesized 16 different qAN1-modified DNA decamer sequences, thus covering all possible combinations of neighboring bases to qAN1 (Table 1). For details of the solid-phase oligonucleotide synthesis, see the Supporting Information.

Conformation and Stability of qAN1-Modified Duplexes. To investigate whether qAN1 affects the secondary structure of DNA duplexes, circular dichroism (CD) was measured on both the modified and the corresponding unmodified duplexes. All spectra show the general characteristics of B-form DNA, a positive band between 260 and $280 \mathrm{~nm}$ and a negative band around $245 \mathrm{~nm}$ (Figures S1 and S2), ${ }^{29}$ suggesting that duplexes modified with qAN1 adopt normal Bform geometry. There are minor variations between $\mathrm{CD}$-spectra of the modified and unmodified duplexes, most likely due to differences in the absorption spectrum between qAN1 and the natural adenine that is being replaced. The long wavelength absorption band of qAN1 is not observed in any of the CD spectra. This is not unexpected, as it was seen neither for the parent compound $\mathrm{qA}$ nor for $\mathrm{tC}^{\mathrm{O}} \cdot{ }^{19,23}$ For other base analogues, such as $\mathrm{tC}$ and 2-AP, the long wavelength absorption band can indeed be observed in CD. ${ }^{30,31}$ The reason for this difference between base analogues is still not understood.

To investigate the effect of the incorporation of qAN1 on duplex stability, we measured the melting temperatures of all qAN1-modified duplexes and the corresponding unmodified duplexes (see Table 1). The melting curves of the qAN1modified duplexes (data not shown) all have the general shape of the corresponding unmodified duplex, strongly indicating that normal B-form DNA duplexes are formed when
Table 1. Melting Temperature of qAN1-Containing Duplexes $\left(T_{\mathrm{m}}{ }^{\mathrm{qAN} 1}\right)$, Unmodified Duplexes $\left(T_{\mathrm{m}}{ }^{\mathrm{A}}\right)$, and the Differences between Them $\left(\Delta T_{\mathrm{m}}\right)$

\begin{tabular}{|c|c|c|c|c|}
\hline $\begin{array}{l}\text { sequence } \\
\text { name }^{a}\end{array}$ & DNA sequence ${ }^{b}$ & $\begin{array}{l}T_{\mathrm{m}}^{\mathrm{qAN} 1} \\
\left({ }^{\circ} \mathrm{C}\right)^{c}\end{array}$ & $\begin{array}{c}T_{\mathrm{m}}{ }^{\mathrm{A}} \\
\left({ }^{\circ} \mathrm{C}\right)^{\mathrm{c}}\end{array}$ & $\begin{array}{l}\Delta T_{\mathrm{m}} \\
\left({ }^{\circ} \mathrm{C}\right)\end{array}$ \\
\hline $\mathrm{AA}$ & $5^{\prime}$-d(CGCAA(qAN1)ATCG)-3' & 40.9 & 43.5 & -2.6 \\
\hline $\mathrm{AC}$ & $5^{\prime}-\mathrm{d}(\mathrm{CGCAA}(\mathbf{q A N 1}) \mathbf{C T C G})-3^{\prime}$ & 49.0 & 47.1 & 1.9 \\
\hline AG & $5^{\prime}-\mathrm{d}(\mathrm{CGCAA}(\mathrm{qAN} \mathbf{1}) \mathrm{GTCG})-3^{\prime}$ & 47.7 & 45.9 & 1.8 \\
\hline AT & $5^{\prime}-\mathrm{d}(\mathrm{CGCAA}(\mathbf{q A N 1})$ TTCG)-3' & 46.4 & 43.4 & 3.0 \\
\hline $\mathrm{CA}$ & $5^{\prime}-\mathrm{d}(\mathrm{CGCAC}(\mathbf{q A N} \mathbf{1}) \mathbf{A T C G})-3^{\prime}$ & 51.4 & 46.5 & 4.9 \\
\hline $\mathrm{CC}$ & $5^{\prime}-\mathrm{d}(\mathrm{CGCAC}(\mathbf{q A N 1}) \mathbf{C T C G})-3^{\prime}$ & 57.1 & 50.3 & 6.8 \\
\hline CG & $5^{\prime}-\mathrm{d}\left(\right.$ CGCAC $($ qAN1) GTCG $)-3^{\prime}$ & 55.0 & 49.5 & 5.5 \\
\hline $\mathrm{CT}$ & $5^{\prime}-\mathrm{d}\left(\mathrm{CGCAC}(\mathbf{q A N} \mathbf{1}) \mathrm{TTCG}^{-}\right)-3^{\prime}$ & 54.0 & 47.3 & 6.7 \\
\hline GA & $5^{\prime}$-d(CGCAG(qAN1)ATCG)-3' & 44.0 & 45.3 & -1.3 \\
\hline GC & $5^{\prime}-\mathrm{d}(\mathrm{CGCAG}(\mathbf{q A N} \mathbf{1}) \mathbf{C T C G})-3^{\prime}$ & 51.2 & 49.2 & 2.0 \\
\hline GG & $5^{\prime}-\mathrm{d}($ CGCAG(qAN1)GTCG)-3' & 50.0 & 48.1 & 1.9 \\
\hline GT & $5^{\prime}-\mathrm{d}(\mathrm{CGCAG}(\mathbf{q A N 1}) \mathrm{TTCG})-3^{\prime}$ & 47.7 & 45.4 & 2.3 \\
\hline TA & $5^{\prime}-\mathrm{d}(\mathrm{CGCAT}$ (qAN1)ATCG)-3' & 43.5 & 41.1 & 2.4 \\
\hline $\mathrm{TC}$ & $5^{\prime}-\mathrm{d}(\mathrm{CGCAT}(\mathbf{q A N 1}) \mathbf{C T C G})-3^{\prime}$ & 48.1 & 43.7 & 4.4 \\
\hline TG & $5^{\prime}-\mathrm{d}($ CGCAT(qAN1)GTCG)-3' & 48.5 & 43.6 & 4.9 \\
\hline TT & $5^{\prime}$-d(CGCAT(qAN1)TTCG)-3' & 47.0 & 40.6 & 6.4 \\
\hline
\end{tabular}

${ }^{a}$ Sequences are named by the bases neighboring qAN1 on the $5^{\prime}$ - and $3^{\prime}$-sides, respectively. ${ }^{b}$ Unmodified sequences contain an adenine instead of qAN1. Duplexes were formed by hybridization with the complementary strand as described in the experimental section. ${ }^{c}$ Samples were prepared in phosphate buffer, $\mathrm{pH} 7.5,123 \mathrm{mM} \mathrm{Na}^{+}$. The melting temperatures were calculated as the maximum of the first derivative of the UV-melting curves with a standard error of $\leq 0.3{ }^{\circ} \mathrm{C}$. For individual error values, see Table S1.

exchanging adenine with qAN1. On average, qAN1 increases the DNA duplex melting temperature $\left(T_{\mathrm{m}}\right)$ by $2.9^{\circ} \mathrm{C}$, which is similar to the increase in stability observed for the parent compound $\mathrm{qA}\left(3.0^{\circ} \mathrm{C}\right) .{ }^{23}$ In general, qAN1 has a stronger stabilizing effect when surrounded by pyrimidines rather than purines. Only two duplexes show a decrease in the melting 
temperature, $\mathrm{AA}$ and $\mathrm{GA}$, where the melting temperature drops by 2.6 and $1.3{ }^{\circ} \mathrm{C}$, respectively. A decrease in the melting temperature was also observed for the qA AA-duplex; however, the decrease was less pronounced $\left(0.3^{\circ} \mathrm{C}\right) .^{23}$ The largest stabilization (average $5.0^{\circ} \mathrm{C}$ ) is observed when a pyrimidine flanks qAN1 on the $5^{\prime}$ side (Table 1 ). This observation is well in line with the results for $\mathrm{qA}$ under similar conditions (phosphate buffer, $\mathrm{pH} 7.5,200 \mathrm{mM} \mathrm{NaCl}$ ). In the case of $\mathrm{qA}$, this phenomenon was suggested to be caused by an increased base-stacking overlap between $\mathrm{qA}$ and $5^{\prime}$-cytosine, as compared to $A$ and $5^{\prime}$-cytosine, due to the extended ring system on $\mathrm{qA}$; an increased stacking effect is significantly less pronounced for neighboring purines. $^{23}$ Here, qAN1, which has a similar extended ring system, gives the same stabilization effect, and thus strengthens this hypothesis. Similar observations have also been made for pyrimidines flanking tricyclic cytosines on the $5^{\prime}$-side. ${ }^{19,30}$ This is not surprising because the ring system extension for the tricyclic cytosines relative to $\mathrm{C}$ is similar to that of $\mathrm{qA}$ and $\mathrm{qAN} 1$ relative to $\mathrm{A}$.

The observed melting temperature dependence on neighboring bases offers the user an opportunity to fine-tune the relative melting temperatures of modified duplexes as compared to their unmodified counterparts. The slight general increase in melting temperature of qAN1-containing duplexes is in general preferable as compared to adenine FBAs such as $2-\mathrm{AP}^{32}$ the pteridine $3-\mathrm{MI}^{33} 6 \mathrm{MAP}, \mathrm{DMAP},{ }^{34}$ and $\mathrm{xA},{ }^{35}$ which all significantly reduce the duplex stability.

To study the base-pairing specificity of qAN1, three duplexes (CT, GA, and TA) were selected for a mismatch study, where the change in melting temperature upon pairing qAN1 with adenine, cytosine, or guanine instead of thymine was investigated. The sequences were chosen to investigate the influence of having only neighboring pyrimidines $(\mathrm{CT})$, purines (GA), or a mix of them (TA). Figure 1 shows the changes in melting temperature for each set of nearest neighbors when replacing thymine in the opposing strand with adenine, cytosine, or guanine (see also Table S2).

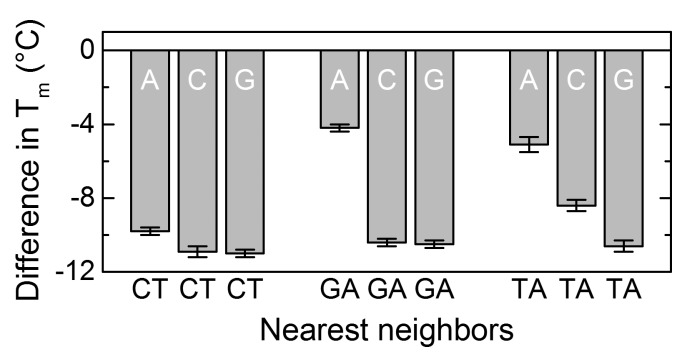

Figure 1. Difference in $T_{\mathrm{m}}$ with standard error between mismatched (A, C, or G opposite qAN1) and the corresponding matched sequences ( $\mathrm{T}$ opposite qAN1) for three different sets of nearest neighbors to qAN1 (CT, GA, and TA). Measurements were performed in phosphate buffer, $\mathrm{pH} 7.5,123 \mathrm{mM} \mathrm{Na}^{+}$.

The melting temperature decreases by 4.2 to $10.9{ }^{\circ} \mathrm{C}$ when a base other than thymine is placed opposite qAN1, indicating that qAN1 is selective toward thymine. When inserting a guanine or cytosine in the opposite strand, the average decrease in melting temperature is 10.5 and $9.8{ }^{\circ} \mathrm{C}$, respectively. Inserting an adenine affects the melting temperature less (on average $6.3{ }^{\circ} \mathrm{C}$ ). For the parent compound $\mathrm{qA}$, the 3 mismatched bases had approximately the same destabilizing effect. The different trend observed here could be a result of the nitrogen in the pyridine ring of qAN1, which offers an additional hydrogen bond, possibility allowing qAN1 to from hydrogen bonds to adenine, cytosine, and guanine. Such base pairs would destabilize the duplex to different extents, with qAN1-adenine being the least destabilizing mismatch (Chart S1). A comparison of the CD spectra of the mismatched sequences with the corresponding matched ones at room temperature indicates that the duplexes are virtually unperturbed, even though the melting temperatures are altered (Figure S3). With a few exceptions, like ${ }^{\text {th }} \mathrm{A}^{36}$ and ${ }^{\mathrm{tz}} \mathrm{A},{ }^{37}$ the specificity of qAN1 for thymine is rare among adenine analogues. For example, the widely used analogue 2-AP forms base pairs not only with thymine but also with cytosine (wobble), adenine (wobble), and guanine (Hoogsteen-type). ${ }^{38}$

In conclusion, the $\mathrm{CD}$, melting, and mismatch data indicate that, like qA, qAN1 is an excellent adenine analogue that does not significantly alter the DNA structure or its stability and, importantly, it base pairs selectively with thymine.

Photophysical Properties of qAN1 in Single- and Double-Stranded DNA. Next, we investigated the photophysical properties of qAN1 in single- and double-stranded DNA (ssDNA and dsDNA; Figure 2 and Table 2). The main findings include a blue-shift in the emission peak $\left(\lambda_{\mathrm{Em}, \max }\right.$ $(\mathrm{ssDNA})=418 \mathrm{~nm}$ and $\left.\lambda_{\mathrm{Em}, \max }(\mathrm{dsDNA})=414 \mathrm{~nm}\right)$ as compared to the qAN1-monomer $\left(\lambda_{\text {Em, } \max }=430 \mathrm{~nm}\right)$ and a greatly improved average quantum yield both in single- and in double-stranded DNA as compared to qA (6.3\% and 5.8\% vs $1.9 \%$ and $0.34 \%$, respectively). For some sequences, we also found a second red-shifted, sequence-dependent emission peak $\left(\lambda_{\mathrm{Em}, \max }=507 \mathrm{~nm}\right)$ or shoulder in the dsDNA spectra. Absorption and emission wavelengths as well as quantum yields and lifetimes for all single- and double-stranded qAN1sequences can be found in Table 2, together with the calculated radiative and nonradiative rate constants.
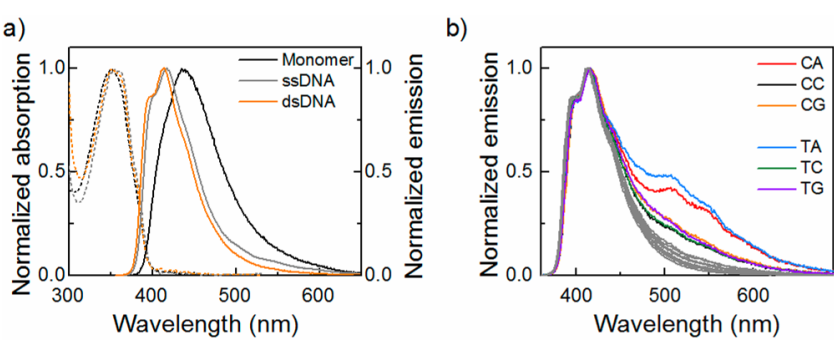

Figure 2. (a) Normalized absorption (dotted lines) and emission (solid lines, $\lambda_{\mathrm{Ex}}=350 \mathrm{~nm}$ ) spectra of qAN1 as a monomer, in ssDNA (sequence AA) and in dsDNA (duplex AA). (b) Normalized emission spectra $\left(\lambda_{\mathrm{Ex}}=350 \mathrm{~nm}\right)$ for all $16 \mathrm{qAN} 1$ modified duplexes. Spectra with a shoulder on the red side are shown in color, and the remaining are in gray. Measurements were performed at room temperature in phosphate buffer, $\mathrm{pH} 7.5,123 \mathrm{mM} \mathrm{Na}$.

Figure 2a shows representative absorption and emission spectra of qAN1 in ssDNA and dsDNA, as well as the corresponding spectra of the monomer. The absorption maximum is virtually the same in all three cases (around 354 $\mathrm{nm}$ ), and, thus, qAN1 keeps its absorption maximum well outside of the absorption band of the natural nucleobases, which do not absorb above $300 \mathrm{~nm}$. $^{39}$ Thus, qAN1 is easily excited selectively inside DNA. This feature of qAN1 is shared with other well-known and useful FBAs such as 6MAP (310 $\mathrm{nm}),{ }^{40}$ DMAP $(330 \mathrm{~nm}),{ }^{40}$ 3-MI $(348 \mathrm{~nm}),{ }^{34}$ 6-MI (340 $\mathrm{nm}),{ }^{34}$ 2-AP $(305 \mathrm{~nm}),{ }^{41}$ boPhpC $(365 \mathrm{~nm}),{ }^{42}$ and the RNA 
Table 2. Photophysical Properties of the 16 Single- and Double-Stranded Sequences Containing qAN1 ${ }^{a}$

\begin{tabular}{|c|c|c|c|c|c|c|c|c|c|c|c|c|}
\hline \multirow[b]{2}{*}{$\mathrm{NN}^{b}$} & \multicolumn{6}{|c|}{ ssDNA } & \multicolumn{6}{|c|}{ dsDNA } \\
\hline & $\begin{array}{c}\lambda_{\mathrm{Abs}} \\
(\mathrm{nm})^{c}\end{array}$ & $\begin{array}{l}\lambda_{\mathrm{Em}} \\
(\mathrm{nm})\end{array}$ & $\Phi_{\mathrm{f}}(\%)^{d}$ & $\langle\tau\rangle(\mathrm{ns})^{e}$ & $\begin{array}{c}k_{\mathrm{r}} \\
\left(10^{7} \mathrm{~s}^{-1}\right)^{f}\end{array}$ & $\begin{array}{c}k_{\mathrm{nr}} \\
\left(10^{8} \mathrm{~s}^{-1}\right)^{f}\end{array}$ & $\begin{array}{c}\lambda_{\mathrm{Abs}} \\
(\mathrm{nm})^{c}\end{array}$ & $\begin{array}{l}\lambda_{\mathrm{Em}} \\
(\mathrm{nm})\end{array}$ & $\Phi_{\mathrm{f}}(\%)^{d}$ & $\langle\tau\rangle(\mathrm{ns})^{e}$ & $\begin{array}{c}k_{\mathrm{r}} \\
\left(10^{7} \mathrm{~s}^{-1}\right)^{f}\end{array}$ & $\begin{array}{c}k_{\mathrm{nr}} \\
\left(10^{8} \mathrm{~s}^{-1}\right)^{f}\end{array}$ \\
\hline AA & 355 & 417 & $21.2 \pm 0.6$ & $5.6 \pm 0.2$ & 3.8 & 1.8 & 352 & 413 & $10.8 \pm 0.4$ & $3.3 \pm 0.2$ & 3.3 & 3.0 \\
\hline $\mathrm{AC}$ & 354 & 418 & $5.4 \pm 0.3$ & $1.4 \pm 0.1$ & 3.9 & 7.1 & 353 & 414 & $4.8 \pm 0.2$ & $1.6 \pm 0.1$ & 3.0 & 6.3 \\
\hline AG & 355 & 417 & $14.3 \pm 0.5$ & $4.1 \pm 0.3$ & 3.5 & 2.4 & 352 & 415 & $9.0 \pm 0.1$ & $3.2 \pm 0.2$ & 2.9 & 3.2 \\
\hline $\mathrm{AT}$ & 354 & 418 & $3.4 \pm 0.1$ & $0.85 \pm 0.07$ & 4.0 & 12 & 351 & 412 & $8.3 \pm 0.3$ & $3.0 \pm 0.2$ & 2.8 & 3.3 \\
\hline CA & 354 & 419 & $5.0 \pm 0.3$ & $1.2 \pm 0.1$ & 4.0 & 8.3 & 354 & 415 & $4.5 \pm 0.2$ & $1.2 \pm 0.1$ & 3.7 & 8.3 \\
\hline $\mathrm{CC}$ & 356 & 419 & $1.8 \pm 0.1$ & $0.50 \pm 0.06$ & 3.7 & 20 & 354 & 416 & $2.8 \pm 0.2$ & $0.82 \pm 0.03$ & 3.4 & 12 \\
\hline CG & 356 & 419 & $2.1 \pm 0.1$ & $0.56 \pm 0.08$ & 3.7 & 18 & 354 & 417 & $2.7 \pm 0.1$ & $0.86 \pm 0.04$ & 3.1 & 12 \\
\hline $\mathrm{CT}$ & 356 & 419 & $1.3 \pm 0.1$ & $0.30 \pm 0.04$ & 4.2 & 33 & 353 & 413 & $3.9 \pm 0.2$ & $1.3 \pm 0.1$ & 3.0 & 7.7 \\
\hline GA & 355 & 417 & $17.6 \pm 0.4$ & $4.7 \pm 0.3$ & 3.7 & 2.1 & 352 & 414 & $8.1 \pm 0.2$ & $2.9 \pm 0.1$ & 2.8 & 3.5 \\
\hline GC & 355 & 418 & $4.6 \pm 0.2$ & $1.1 \pm 0.1$ & 4.1 & 9.1 & 353 & 415 & $3.0 \pm 0.1$ & $1.0 \pm 0.1$ & 3.0 & 10 \\
\hline GG & 355 & 417 & $14.9 \pm 0.5$ & $4.2 \pm 0.4$ & 3.6 & 2.4 & 351 & 414 & $7.6 \pm 0.2$ & $2.8 \pm 0.1$ & 2.7 & 3.6 \\
\hline GT & 354 & 418 & $2.7 \pm 0.1$ & $0.62 \pm 0.11$ & 4.3 & 16 & 351 & 412 & $3.4 \pm 0.1$ & $1.4 \pm 0.1$ & 2.4 & 7.1 \\
\hline $\mathrm{TA}$ & 356 & 420 & $2.8 \pm 0.1$ & $0.71 \pm 0.10$ & 3.9 & 14 & 354 & 416 & $6.6 \pm 0.5$ & $2.1 \pm 0.1$ & 3.2 & 4.8 \\
\hline $\mathrm{TC}$ & 356 & 419 & $1.1 \pm 0.1$ & $0.35 \pm 0.07$ & 3.0 & 29 & 354 & 415 & $4.7 \pm 0.2$ & $1.5 \pm 0.1$ & 3.2 & 6.7 \\
\hline TG & 356 & 420 & $1.5 \pm 0.1$ & $0.43 \pm 0.06$ & 3.5 & 23 & 353 & 416 & $4.5 \pm 0.2$ & $1.7 \pm 0.1$ & 2.6 & 5.9 \\
\hline $\mathrm{TT}$ & 356 & 420 & $0.9 \pm 0.1$ & $0.22 \pm 0.03$ & 4.0 & 45 & 353 & 414 & $7.3 \pm 0.4$ & $2.8 \pm 0.1$ & 2.6 & 3.6 \\
\hline
\end{tabular}

${ }^{a}$ Measurements were performed at room temperature in phosphate buffer, $\mathrm{pH} 7.5,123 \mathrm{mM} \mathrm{Na}{ }^{+}$. The reported quantum yields and fluorescence lifetimes are an average of two or more experiments. ${ }^{b}$ Sequences were named according to the nucleosides surrounding qAN1; full sequences can be found in Table $1 .{ }^{c}$ In some cases, depending on nearest neighbors and ssDNA/dsDNA, the main absorption band is split into two closely lying vibronic peaks. In these cases, we report the maximum of the highest energy transition. Molar absorptivities of the individual ssDNA and dsDNA range between $8400-9800 \mathrm{M}^{-1} \mathrm{~cm}^{-1}$ and $7800-9500 \mathrm{M}^{-1} \mathrm{~cm}^{-1}$, respectively, and can be found in Table S3. ${ }^{d}$ Quantum yields including standard error were determined for emission profiles as shown in Figure $2 \mathrm{~b}$, that is, including the shoulder at $505 \mathrm{~nm}$ for certain sequences resulting in apparent QYs, with quinine sulfate as reference $\left(\Phi_{\mathrm{f}}=54.6 \%\right.$ in $\left.0.5 \mathrm{M} \mathrm{H}_{2} \mathrm{SO}_{4}\right)$, using an excitation wavelength of $350 \mathrm{~nm}$. ${ }^{e}$ Fluorescence decays were measured using a TCSPC setup with a laser diode emitting at $377 \mathrm{~nm}$ and emission collection at $415 \mathrm{~nm} .{ }^{f_{\text {Radiative }}}\left(k_{\mathrm{r}}\right)$ and nonradiative $\left(k_{\mathrm{nr}}\right)$ decay rates were calculated from the measured quantum yields and lifetimes (eqs S2 and S3).

analogues ${ }^{\text {th }} \mathrm{A}(341 \mathrm{~nm}),{ }^{\text {th }} \mathrm{G}(320 \mathrm{~nm}),{ }^{\text {th }} \mathrm{C}(321 \mathrm{~nm})$, and ${ }^{\text {th }} \mathrm{U}$ $(304 \mathrm{~nm})^{43}$

The main emission peak, found at $417-420 \mathrm{~nm}$ in ssDNA and 412-417 nm in dsDNA, shows a slight blue-shift as compared to the free monomer in water $(430 \mathrm{~nm})$, and its position is virtually insensitive to neighboring bases. When situated inside DNA, the emission of qAN1 is more structured (both single- and double-stranded) than that of the free monomer, ${ }^{22}$ with a distinct shoulder on the blue side of the emission peak at approximately $402 \mathrm{~nm}$ in ssDNA and at 396 $\mathrm{nm}$ in dsDNA. The more structured emission inside DNA indicates that the probe is firmly stacked. The slight blue-shift upon incorporation into DNA can be explained by the less polar environment inside DNA in combination with an increased dipole moment in the excited state, ${ }^{3}$ yielding a higher degree of solvent relaxation of the excited state in solution compared to in DNA. This also explains why the blueshift is slightly stronger in dsDNA as compared to that in ssDNA.

Figure $2 \mathrm{~b}$ shows the normalized emission spectra of all qAN1 duplexes excited at $350 \mathrm{~nm}$. Sequences with a pyrimidine $5^{\prime}$ to qAN1, except those with thymine on the $3^{\prime}$-position, show a significant shoulder on the red side of the emission maximum at approximately $507 \mathrm{~nm}$, which is not present for the ssDNA (Figure S4). As other FBAs, for example, 8-azaG, ${ }^{44}$ show $\mathrm{pH}$ dependent emission, and we have previously shown that protonation of the qAN1 monomer results in an emission at approximately $505 \mathrm{~nm},{ }^{22}$ we measured emission and excitation spectra for CA- and AA-duplexes at $\mathrm{pH}$ 5. Indeed, the emission of qAN1 in DNA is $\mathrm{pH}$ dependent. However, the excitation and emission spectra of the duplexes at $\mathrm{pH} 5$ do not correspond to the species causing the $507 \mathrm{~nm}$ shoulder in the DNA emission spectra at neutral $\mathrm{pH}$, and, consequently, the shoulder cannot be explained by a simple pH-effect (Figure S5). Instead, and because the effect is not seen in the absorption spectra, we suggest that the shoulder is a result of tautomerization in the excited state, in which a hydrogen on the $\mathrm{N}$ in the middle ring shifts to the $\mathrm{N}$ on the outer ring of qAN1. This would explain why the same effect was not observed for the parent compound $\mathrm{qA}$, which lacks a nitrogen in the outer ring. ${ }^{23}$ The variation we observe between DNA sequences is most likely a result of the different stacking patterns, which depend on the nearest neighboring bases and their effect on the stability of the tautomeric form of qAN1.

A significant increase in the quantum yield of $\mathrm{qAN} 1$ is observed as compared to that of qA both in ssDNA $\left(\left\langle\Phi_{\mathrm{f}}\right\rangle=\right.$ $6.3 \%$ vs $1.9 \%)$ and dsDNA $\left(\left\langle\Phi_{\mathrm{f}}\right\rangle=5.8 \%\right.$ vs $0.3 \%$; Figure $\left.\mathrm{S} 6\right)$; that is, the average quenching of qAN1 upon incorporation into DNA is approximately 3 -fold $\left(\Phi_{\mathrm{f}}=18 \%\right.$ for the qAN1 monomer). Other base analogues, for example, $2-\mathrm{AP},{ }^{45}$ the pteridines, ${ }^{34}$ and pyrrolo- $\mathrm{dC},{ }^{46}$ are also known to be quenched, often more severely, upon incorporation into nucleic acids. The mechanism of quenching is generally not completely characterized and normally involves several mechanisms, including $\pi$-stacking with adjacent bases in the same strand and energy/electron transfer between the FBA and the surrounding bases.

As can be seen in Table 2, the quantum yield of qAN1 flanked by two purines in ssDNA is virtually unaffected (average $17 \%$, as compared to $18 \%$ for the monomer). On the other hand, two pyrimidines surrounding qAN1 results in a 10-20-fold quenching in ssDNA, with thymine being the most efficient quencher. In dsDNA, the duplexes with neighboring purines still give the highest quantum yields (7.6-10.8\%). However, the difference between purines and pyrimidines is not as pronounced as for ssDNA. All sequences with a neighboring 
thymine show a higher quantum yield in dsDNA than in ssDNA. This is possibly because quenching by thymine requires stacking with qAN1, and the inherent helical twist of the duplex structure prevents a perfect overlap between qAN1 and thymine. The fact that qAN1 is not primarily quenched by guanine is unusual for a FBA, but this has also been reported for the parent compound $\mathrm{qA}$ as well as for the cytosine analogues $\mathrm{tC}$ and $\mathrm{tC}^{\mathrm{O}} \cdot{ }^{19,20,23}$ For other FBAs such as $2-\mathrm{AP},{ }^{47}$ triazole adenine, ${ }^{48}$ and $\mathrm{BPP},{ }^{49}$ guanine is often an efficient quencher. This is commonly attributed to the high electrondonating properties of guanine, enabling quenching by photoinduced electron transfer to the FBA. ${ }^{50}$ Depending on the redox properties of the FBA, the transfer of electrons could also be from the FBA and then primarily to pyrimidines, which have a higher tendency to attract electrons than purines. For example, this was reported for pyrene-labeled uridine in pentamers $^{51}$ and is also one of the plausible reasons for the quenching effect found for qAN1 in this study.

The higher quantum yield of the monomer, in combination with the lower amount of quenching in DNA and a higher molar absorptivity (on average $9000 \mathrm{M}^{-1} \mathrm{~cm}^{-1}$ in ssDNA and $8700 \mathrm{M}^{-1} \mathrm{~cm}^{-1}$ in dsDNA; Table S3), means that qAN1 is much brighter in DNA than qA. The average brightness $\left(\Phi_{\mathrm{f}} \cdot \varepsilon=\right.$ 510 ) is increased 29-fold as compared to qA inside dsDNA, which is very promising for applications of this novel FBA. Other base analogues generally have a lower brightness inside dsDNA; however, truly comparative data are difficult to find, as most base analogues have only been measured in one or a few different base surroundings. For example, brightness values between 40 and 80 have been reported for $2-\mathrm{AP},{ }^{45,52,53}$ around 150 for 6-MAP, ${ }^{40,54} 200$ for 8-vd-A, ${ }^{55,56} 180$ for pyrrolo-dC, ${ }^{57}$ and 330 for ${ }^{\text {th }} \mathrm{G}^{43}$ 3-MI exhibits brightness values between 390 and 3800 depending on sequence; ${ }^{3,58}$ however, 3-MI does not participate in base pairing interactions due to its unfavorable structural features. ${ }^{34}$ The cytosine analogues $\mathrm{tC}$ and $\mathrm{tC}^{\mathrm{O}}$ are brighter than qAN1 inside DNA with brightness values of $760^{20,59}$ and $2000,{ }^{19}$ respectively.

For most qAN1 sequences, the decrease in quantum yield is accompanied by a shortening of the fluorescence lifetime (Table 2). The majority of the ssDNA decays was best fitted to triexponential functions, while the majority of dsDNA decays was fitted to biexponential functions (Figures S7 and S8; Tables S4 and S5), indicating a firm positioning of qAN1 in dsDNA. The amplitude weighted average lifetime is between 0.22 and $5.6 \mathrm{~ns}$ for ssDNA and between 0.82 and $3.3 \mathrm{~ns}$ for dsDNA, while the qAN1-monomer in solution has a lifetime of $4.8 \mathrm{~ns}$. In ssDNA and with $\mathrm{AA}$ as neighboring bases, qAN1 has a longer lifetime than in its monomeric form. This correlates with the same sequence being the only one where qAN1 shows a higher quantum yield than as a monomer. The radiative rate constant is quite stable in dsDNA (average $3.0 \times 10^{7} \mathrm{~s}^{-1}$ ) and slightly shorter than that of the monomer $\left(3.76 \times 10^{7} \mathrm{~s}^{-1}\right)$. However, the nonradiative rate constant generally increases with decreasing quantum yield, especially for CC, GC, and CG, the three sequences with the lowest quantum yield. The average value of $6.3 \times 10^{8} \mathrm{~s}^{-1}$ is significantly higher than that of the monomer $\left(1.71 \times 10^{8} \mathrm{~s}^{-1}\right)$. The larger difference in the nonradiative- as compared to the radiative rate-constant between qAN1 in duplex and as a monomer indicates that the lower quantum yield in dsDNA primarily originates from more efficient nonradiative decay pathways in duplexes, a quenching most likely introduced by the close proximity of the neighboring bases.
Spectral Properties, Conformation, and Stability of Duplexes Containing $q A_{\text {nitror }}$ an Adenine Analogue FRET-Acceptor. The introduction of a nitro-group in a chromophore generally red-shifts the absorption and quenches the fluorescence. ${ }^{60,61}$ Therefore, a straightforward design strategy for FBA FRET-acceptors is to add a nitro-group to a FBA scaffold. This strategy has previously proved successful in the design of $\mathrm{tC}_{\text {nitro }}$ as a FRET-acceptor for $\mathrm{tC} / \mathrm{tC}^{\mathrm{O}} \cdot{ }^{16} \mathrm{To}$ find a suitable acceptor for $\mathrm{qAN1}$, we therefore synthesized $\mathrm{qA}_{\text {nitro }}$ (Chart 1) and investigated its photophysical and base analogue properties by incorporating it into two different decamers differing only in the bases neighboring $\mathrm{qA}_{\text {nitro }}$ (Table 3).

Table 3. Melting Temperatures of $\mathrm{qA}_{\text {nitro }}$-Containing Duplexes $\left(T_{\mathrm{m}}{ }^{\mathrm{qAnitro}}\right)$, Unmodified Duplexes $\left(T_{\mathrm{m}}{ }^{\mathrm{A}}\right)$, and the Difference between Them $\left(\Delta T_{\mathrm{m}}\right)$

\begin{tabular}{|c|c|c|c|c|}
\hline $\begin{array}{l}\text { sequence } \\
\text { name }^{a}\end{array}$ & DNA sequence ${ }^{b, c}$ & $\begin{array}{c}T_{\mathrm{m}}{ }^{\text {qAnitro }} \\
\left({ }^{\circ} \mathrm{C}\right)^{d}\end{array}$ & $\begin{array}{c}T_{\mathrm{m}}^{\mathrm{A}} \\
\left({ }^{\circ} \mathrm{C}\right)^{d}\end{array}$ & $\begin{array}{l}\Delta T_{\mathrm{m}} \\
\left({ }^{\circ} \mathrm{C}\right)\end{array}$ \\
\hline $\mathrm{AT}-\mathrm{qA}_{\text {nitro }}$ & $5^{\prime}-\mathrm{d}(\mathrm{CGCAA}(\mathrm{X})$ TTCG $)-3^{\prime}$ & 45.9 & 43.4 & 5 \\
\hline TA-qA & $5^{\prime}-\mathrm{d}(\mathrm{CGCAT}(\mathbf{X})$ ATCG $)-3^{\prime}$ & 43.8 & 41.1 & 2.7 \\
\hline \multicolumn{5}{|c|}{$\begin{array}{l}\text { oring } \mathrm{qA}_{\text {nitro }} 5^{\prime} \text { to } 3^{\prime} .{ }^{b} \text { For } \\
\text { odified sequences, } \mathrm{X}=\mathrm{A} \text {. } \\
\text { potnotes of Table } 1 \text {. The } \\
\text { the maximum of the first } \\
\text { standard error of } \leq 0.2^{\circ} \mathrm{C} \text {. }\end{array}$} \\
\hline
\end{tabular}

The lowest energy absorption maximum of $\mathrm{qA}_{\text {nitro }}$ is situated at $431 \mathrm{~nm}$ for the free monomer, whereas in ssDNA and dsDNA it is red-shifted to 439 and $435 \mathrm{~nm}$, respectively (see Figure S9). The molar absorptivity is $5800 \mathrm{M}^{-1} \mathrm{~cm}^{-1}(431 \mathrm{~nm})$ for the monomer in water and $5400 \mathrm{M}^{-1} \mathrm{~cm}^{-1}(435 \mathrm{~nm})$ in dsDNA. In fluorescence measurements, we find that $\mathrm{qA}_{\text {nitro }}$ as expected, is virtually nonemissive (data not shown).

To evaluate duplex conformation and stability upon exchanging a normal adenine for $\mathrm{qA}_{\text {nitro }} \mathrm{CD}$ and melting temperatures were measured on both the modified duplexes and the corresponding reference duplexes. CD spectra show Bform DNA characteristics, and there is no significant difference between the $\mathrm{CD}$-spectra of $\mathrm{qA}_{\text {nitro-modified and the corre- }}$ sponding reference duplexes (Figure S10). The melting temperature of the $\mathrm{qA}_{\text {nitro }}$ modified duplexes are almost identical to the melting temperatures found for the corresponding qAN1 modified duplexes (45.9 vs $46.4{ }^{\circ} \mathrm{C}$ for AT duplexes and 43.8 vs $43.5^{\circ} \mathrm{C}$ for TA duplexes). On average, the melting temperature increases by $2.6^{\circ} \mathrm{C}$ for duplexes with $\mathrm{qA}_{\text {nitro }}$ as compared to the corresponding ones with adenine (see Table 3). The slight increase in melting temperature shows that $\mathrm{qA}_{\text {nitro }}$ does not significantly affect the DNA stability. In combination with the $\mathrm{CD}$ data, this suggests that $\mathrm{qA}_{\text {nitro }}$ is also a good, nonperturbing base analogue.

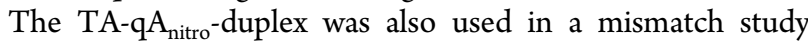
measuring melting temperatures and $C D$. Replacing the thymine opposite $\mathrm{qA}_{\text {nitro }}$ with either adenine, cytosine, or guanine results in a decrease in the melting temperature of 11.2, 7.7, and $8.4^{\circ} \mathrm{C}$, respectively (see Table S6). In addition to Bform characteristics, the $\mathrm{CD}$ spectra of the mismatched sequences show a minor $C D$ effect in the spectral region originating from the $\mathrm{qA}_{\text {nitro }}$ chromophore (Figure S11). In conclusion, the $\mathrm{CD}$ and melting experiments suggest that $\mathrm{qA}_{\text {nitro }}$ not only leaves the structure and stability of DNA virtually unperturbed, but that it also specifically base pairs with 
T. The smaller destabilization opposite A observed for qAN1 (vide supra) is, as expected, not found for $\mathrm{qA}_{\text {nitro }}$ presumably due to the lack of $\mathrm{N}$ in the outer ring.

FRET between qAN1 and $q A_{\text {nitro }}$ in DNA. FRET between two molecules requires a spectral overlap between the donor emission and acceptor absorption (see eqs S5 and S6). Figure 3 shows the overlap between the normalized qAN1 emission and $\mathrm{qA}_{\text {nitro }}$ absorption inside dsDNA.

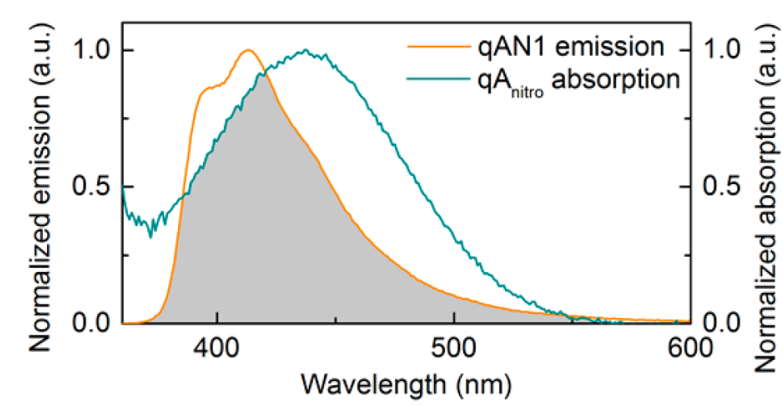

Figure 3. Spectral overlap between $\mathrm{qAN1}$ emission $\left(\lambda_{\mathrm{Ex}}=350 \mathrm{~nm}\right)$ and $\mathrm{qA}_{\text {nitro }}$ absorption in dsDNA. Spectra are normalized at their longwavelength maxima. Measurements were performed at room temperature in phosphate buffer, $\mathrm{pH} 7.5,123 \mathrm{mM} \mathrm{Na}^{+}$.

Using eq S6 with the orientation factor, $\kappa^{2}=2 / 3$ (this value is only correct for freely rotating probes and used here purely for comparative purposes), the Förster radius, $R_{0}$, is calculated to be $22 \AA$ on average for this FRET-pair ( $25 \AA$ for AA, which has the highest quantum yield), reflecting the possibility to monitor distances corresponding to almost 1.5 turns of the BDNA helix. ${ }^{16}$ The value of $\kappa^{2}$ varies with the relative orientation of the donor and acceptor (see eq S7) and, thus, is expected to change with the number of bases separating the donor and acceptor within the DNA.

To test the actual FRET efficiency for different base separations between $\mathrm{qAN} 1$ and $\mathrm{qA}_{\text {nitro }}$ eight DNA strands were designed, three donor strands containing qAN1 (all with AA as nearest neighbors), four complementary acceptor strands containing $\mathrm{qA}_{\text {nitro, }}$ and one unmodified complementary strand (see Table 4). The base analogues were positioned to allow the formation of duplexes with 2-13 bases separating the donor and acceptor (Table S7).

First, the quantum yields of qAN1 at the three donor positions were measured and found to differ slightly with

\section{Table 4. Sequences of 33-mers Used in the FRET-Study}

\begin{tabular}{|c|c|}
\hline sequence name ${ }^{a}$ & DNA sequence ${ }^{b}$ \\
\hline D7 & $5^{\prime}$-d(CGA TCA (qAN1)AA AAA ATT X)-3' \\
\hline D9 & $5^{\prime}$-d(CGA TCA AA(qAN1) AAA ATT X)-3' \\
\hline D11 & $5^{\prime}$-d(CGA TCA AAA A(qAN1)A ATT X)-3' \\
\hline A13 & $5^{\prime}$-d(Y TAT ( $\left(\mathbf{A A}_{\text {nitro }}\right)$ AT CGT AAT Z)-3' \\
\hline A14 & $5^{\prime}$-d(Y TAT A(qA $\left.\mathbf{A}_{\text {nitro }}\right)$ T CGT AAT Z)-3' \\
\hline A19 & $5^{\prime}$-d(Y TAT AAT CGT ( $\left.\mathbf{q} \mathbf{A}_{\text {nitro }}\right)$ AT Z)-3' \\
\hline $\mathrm{A} 20$ & $5^{\prime}$-d(Y TAT AAT CGT A( $\left.\left(\mathbf{q A}_{\text {nitro }}\right) \mathrm{T} \mathrm{Z}\right)-3^{\prime}$ \\
\hline A0 & $5^{\prime}$-d(Y TAT AAT CGT AAT Z)-3' \\
\hline
\end{tabular}

${ }^{a}$ Sequences are named by the donor (D)/acceptor (A) position from the $5^{\prime}$-end. ${ }^{b}$ Duplexes were formed by hybridization with their complementary strand as described in the experimental section. Samples were prepared in phosphate buffer, $\mathrm{pH} 7.5,123 \mathrm{mM} \mathrm{Na}^{+} . \mathrm{X}=$ ACG ATT ATA AGG AGG AGG, Y = CCT CCT CCT, $\mathrm{Z}=$ TTT TTT TGA TCG. position (Table S8). For all 12 base-separations, the FRET efficiency was determined using the decrease in steady-state emission or shortening of average lifetime of qAN1 (see Figure 4 and eq S4; for detailed fitting parameters and FRET efficiencies, see Tables S7 and S9).

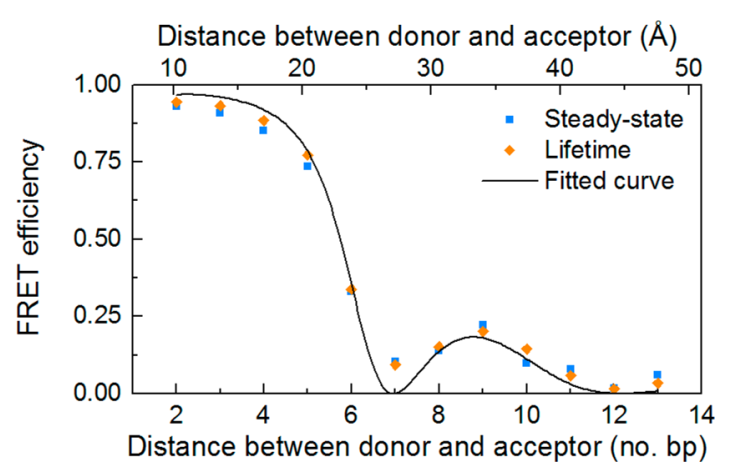

Figure 4. FRET efficiency as a function of number of base-pairs separating the donor and acceptor. Squares and diamonds mark data from steady-state and lifetime measurements, respectively. The line shows the curve fitted to the data based on FRET-theory (see experimental section in the Supporting Information). Measurements were performed at room temperature in phosphate buffer, $\mathrm{pH} 7.5,123$ $\mathrm{mM} \mathrm{Na}{ }^{+}$.

As can clearly be seen in Figure 4, the FRET-efficiency is high at short distances, but decreases sharply when about 5 base-pairs (bp) separate the donor and acceptor, and then oscillates between higher and lower values. This is the same pattern that was found for the cytosine FRET-pair, $\mathrm{tC}^{\mathrm{O}}-$ $\mathrm{tC}_{\text {nitro, }}{ }^{16}$ and is the expected pattern for FRET-pairs firmly positioned in double stranded DNA, because both the distance and the orientation between the chromophores change when the number of separating bases is increased. Hence, these data suggest that our adenine analogues are firmly stacked inside the DNA duplex. An in-house designed MATLAB script was used to fit a theoretical curve to the measured data (see experimental section in the Supporting Information). The optimal fit is obtained for an overlap integral of $1.43 \times 10^{14} \mathrm{M}^{-1} \mathrm{~cm}^{-1} \mathrm{~nm}^{4}$ and a phase angle (the angle between the donor and acceptor transition dipole moments) of $33.3^{\circ}$. Using the spectral profiles of $\mathrm{qAN} 1$ and $\mathrm{qA}_{\text {nitro }}$ the overlap integral is calculated to be 1.4 $\times 10^{14} \mathrm{M}^{-1} \mathrm{~cm}^{-1} \mathrm{~nm}^{4}$, which indeed is close to the fitted value. Using time-dependent density functional theory (TDDFT)calculations, the orientation of the transition dipole moments of qAN1 and $\mathrm{qA}_{\text {nitro }}$ has been predicted, and the associated phase angle is $41^{\circ}$ (experimentally determined transition dipole moments of qAN1 and $\mathrm{qA}_{\text {nitro }}$ as has been performed for the tC-family ${ }^{19,59,62}$ are the subject of a separate study; manuscript in preparation).

The excellent FRET-dependence (Figure 4) for our new FRET-pair strongly suggests that $\mathrm{qAN} 1-\mathrm{qA}_{\text {nitro }}$ is a promising complement to our already existing $\mathrm{tC}^{\mathrm{o}}-\mathrm{tC}_{\text {nitro }}$ FRET-pair that will enable replacement not only of cytosines but also of adenines inside nucleic acids, which will greatly expand the usefulness of base-base FRET in studies where the investigated nucleic acid sequence cannot be altered. An additional and important advantage with the new adenine FRET-pair is that it can be combined with the already existing cytosine FRET-pair. Using $\mathrm{tC}_{\text {nitro }}$ as an acceptor for qAN1 gives an average $R_{0}$ of 22 $\AA$ (for $\kappa^{2}=2 / 3$ ), while $\mathrm{tC}^{\mathrm{o}}$ as a donor for $\mathrm{qA}_{\text {nitro }}$ results in an average $R_{0}$ of $28 \AA$. The potential to cross-use these base 
analogues gives even more possibilities in the design of FRET studies, and, consequently, our FBAs now cover not only two but 3 of the 10 possible base-base FRET-pair combinations. Moreover, one significant advantage of the combination of cytosine and adenine analogues is that through base complementarity it is now possible to access any sequence position in a duplex by combining our four FRET-probes.

Probing Conformational Changes with $q A N 1-q A_{\text {nitro }}$ FRET. To illustrate the potential of using our $q A N 1-\mathrm{qA}_{\text {nitro }}$ FRET-pair for resolving even very small structural variations in DNA upon any molecular interactions, we examined the conformational changes of DNA upon netropsin binding. Netropsin is an established minor groove binder that preferentially binds to short (4-5 bp) AT-rich sequences. ${ }^{63-65}$ Here, our adenine analogue probes offer a valuable sequence flexibility; they can be placed either in- or outside a binding site. Furthermore, we here have the possibility to challenge the base analogue properties of our probes when exchanging natural adenines inside the netropsin binding sites.

The same FBA sequences as in the FRET-study in Figure 4 (Table 4), which contain three netropsin binding sites (see note $\mathrm{S} 1$ ), were utilized here. In the measurements, we used duplexes with 4-11 bases between the donor and acceptor, as these separations give energy transfer rates most sensitive to structural changes. Even though our base analogues only add steric bulk in the major groove and leave recognition patterns in the minor groove unaffected, we still started by establishing the binding behavior of netropsin using CD (see note S2). To ensure binding site saturation, while keeping unspecific interactions at a minimum, we added netropsin in excess $(12: 1)$, which resulted in a similar induced CD-response for all duplexes (Figure S13). The FRET-efficiency for each base separation was determined using both steady-state and timeresolved emission and is shown in Figure 5 (see also Tables S10-12).

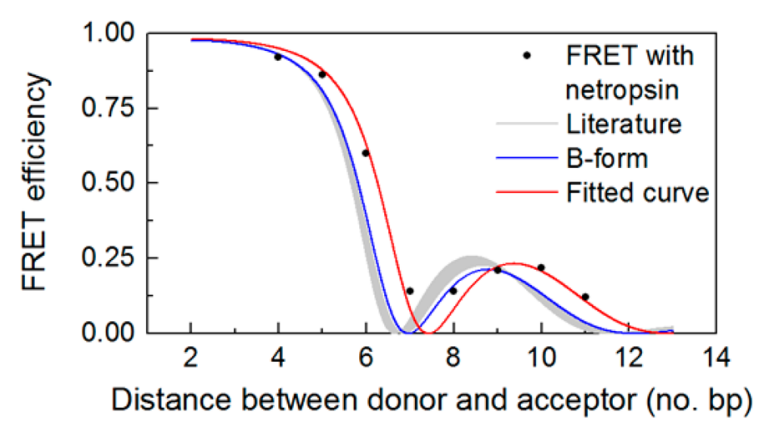

Figure 5. FRET-efficiency as a function of number of base pairs separating the donor and acceptor. Dots mark the measured FRETefficiency with netropsin bound (the average between steady-state and lifetime measurements). Red line shows the best fit to the data based on FRET-theory (see experimental section in the Supporting Information). The blue line shows the expected curve for B-DNA. The gray area shows the range possible if each netropsin molecule overwinds the DNA by $3.1-10.5^{\circ}$. Measurements performed at room temperature in phosphate buffer, $\mathrm{pH} 7.5,123 \mathrm{mM} \mathrm{Na}^{+}$.

The measured data clearly show that netropsin causes a structural change (dots versus blue line in Figure 5). To determine the nature of this change, we fitted the data to the same FRET-model used for B-form DNA in Figure 4, allowing the helical twist and rise to vary, but keeping the overlap intergral and phase angle constant at the values calculated above. The best fit is obtained with a helical twist and rise of $32.2 \pm 0.8^{\circ}$ and $3.15 \pm 0.13 \AA$, respectively. This corresponds to a small, but significant, decrease in the helical twist and rise of DNA by $2.1^{\circ}$ and $0.25 \AA$, respectively, upon binding of netropsin.

The effect of netropsin binding has previously been studied by a broad range of techniques such as sedimentation, ${ }^{66} \mathrm{X}$-ray crystallography, ${ }^{63}$ gel electrophoresis, ${ }^{67,68}$ electric LD, ${ }^{69}$ NMR and $\mathrm{MD},{ }^{68}$ and magnetic tweezers. ${ }^{64}$ Our results are in line with these previous reports in the sense that they also show a minute effect on the twist angle and helical rise, but at the same time contrasts those findings, because they generally report an overwinding of the DNA (reported values generally between $3.1^{\circ}$ and $10.5^{\circ}$ per netropsin, ${ }^{64,66,67}$ with a few exceptions ${ }^{63,68}$ ) or an increase in the helical rise. ${ }^{69}$ To verify that our data indeed cannot be explained by the small overwinding previously reported, we simulated the FRET-efficiency patterns using those values (Figure 5, gray area). This unambiguously shows that our FRET-data do not support an increased helical twist as compared to B-form DNA. Moreover, locking the helical rise to $3.4 \AA$ in the fitting model drastically lowers the quality of the fit, indicating that, while small, the decrease in helical rise is also significant (see note S3). The variations as compared to previous data may be influenced by the difference in DNA sequence between the reports as well as the fact that we use short DNA-duplexes whose relaxation is not hindered upon netropsin binding, whereas previous investigations use long, mixed-sequence DNA, that is often either constrained or not in equilibrium.

With this study, we demonstrate the power of our adenineadenine FRET-pair for monitoring very small distance and orientation changes in DNA structure, and obtain data on netropsin DNA binding that add new insight into this archetypal interaction. Our findings warrant further studies of this conformational change, and, in particular, we plan to strengthen our conclusion in a more comprehensive investigation using a larger set of DNA sequences containing netropsin binding sites of varying nature. We envision that our FBA FRET-pair can be used in a wide variety of applications to study the detailed changes in DNA structure and dynamics that normally accompany interactions between DNA and small ligands, peptides, other nucleic acids, and proteins such as those involved in replication and transcription.

\section{CONCLUSION}

In summary, two quadracyclic adenine analogues, qAN1 and $\mathrm{qA}_{\text {nitro }}$, have been evaluated as DNA FBAs and as FRET-donor and -acceptor, respectively. Both compounds are available through a reliable and high-yielding synthetic route that affords the phosphoramidite monomers, which can subsequently be incorporated into DNA by standard oligonucleotide synthesis methods. We anticipate that this route will prove to be a useful and general pathway to base-modified 2'-deoxyadenosine derivatives. We show that $\mathrm{qAN} 1-$ and $\mathrm{qA}_{\text {nitro-containing }}$ duplexes remain in the $\mathrm{B}$-form and that the nucleobase analogues selectively base-pair with thymine. We find the quantum yield inside DNA to be almost 20 times higher than for the parent compound $\mathrm{qA}$ and a brightness value of 510, which is well beyond other fluorescent adenine analogues such as 2-AP, which has a brightness of around 50 in dsDNA. As a result of its excellent photophysical and base analogue properties, we demonstrate that $\mathrm{qAN} 1$ as a donor together with $\mathrm{qA}_{\text {nitro }}$ as an acceptor constitute our second base analogue 
FRET-pair. Using netropsin-binding, we also show the potential of the new FRET-pair for studying small changes to DNA conformation. The chromophores of our FRET-pair can also be used in combination with $\mathrm{tC}^{\mathrm{O}}$ as the donor or $\mathrm{tC}_{\text {nitro }}$ as the acceptor. Thus, we now provide four different FRET-pairs covering 3 of the 10 possible base combinations with $R_{0}$ values ranging from 22 to $28 \AA$. Additionally, through C-G- and A-Tbase complementarity, all positions in a DNA duplex can be accessed using these four FBAs. Our ultimate goal is to provide base analogue FRET-pairs for all natural bases, and our current study is a significant step toward achieving this.

\section{ASSOCIATED CONTENT}

\section{S Supporting Information}

The Supporting Information is available free of charge on the ACS Publications website at DOI: 10.1021/jacs.7b04517.

Synthesis and characterization of the adenine analogues; oligonucleotide synthesis and photophysical experimental section; and Figures S1-S13, Tables S1-S12, Chart $\mathrm{S} 1$, and notes $\mathrm{S} 1-\mathrm{S} 3$ (PDF)

\section{AUTHOR INFORMATION}

\section{Corresponding Author}

*marcus.wilhelmsson@chalmers.se

\section{ORCID 1}

Moa S. Wranne: 0000-0003-3315-8288

Anders Foller Füchtbauer: 0000-0003-0223-5754

Blaise Dumat: 0000-0002-0455-7282

Mattias Bood: 0000-0003-1644-6915

Afaf H. El-Sagheer: 0000-0001-8706-1292

Tom Brown: 0000-0002-6538-3036

Henrik Gradén: 0000-0003-3103-4388

\section{Present Address}

"Laboratory of Biomolecules CNRS UMR7203, UPMC Université Paris 6, Ecole Normale Supérieur F-75005, Paris.

\section{Notes}

The authors declare no competing financial interest.

\section{ACKNOWLEDGMENTS}

This work was supported by the Swedish Research Council (VR) [2013-4375] and the Swedish Foundation for Strategic Research (SSF) [ID14-0036]. A.H.E.-S. is supported by UK BBSRC grant BB/J001694/2 (Extending the boundaries of nucleic acid chemistry). We thank Associate Professor Maria Abrahamsson for fruitful discussions regarding the interpretation of TCSPC data and Professor Björn Åkerman for valuable advice on the netropsin study.

\section{REFERENCES}

(1) Fluorescent Analogs of Biomolecular Building Blocks, Design and Applications; Wilhelmsson, L. M., Tor, Y., Eds.; John Wiley: Hoboken, NJ, 2016.

(2) Tsien, R. Y. Annu. Rev. Biochem. 1998, 67, 509.

(3) Lakowicz, J. R. Principles of Fluorescence Spectroscopy, 3rd ed.; Springer: New York, 2006.

(4) Hell, S. W. Nat. Biotechnol. 2003, 21, 1347.

(5) Iqbal, A.; Arslan, S.; Okumus, B.; Wilson, T. J.; Giraud, G.; Norman, D. G.; Ha, T.; Lilley, D. M. J. Proc. Natl. Acad. Sci. U. S. A. 2008, 105, 11176

(6) Kato, T.; Kashida, H.; Kishida, H.; Yada, H.; Okamoto, H.; Asanuma, H. J. Am. Chem. Soc. 2013, 135, 741.

(7) Preus, S.; Wilhelmsson, L. M. ChemBioChem 2012, 13, 1990.
(8) Roy, R; Hohng, S.; Ha, T. Nat. Methods 2008, 5, 507.

(9) Stryer, L.; Haugland, R. P. Proc. Natl. Acad. Sci. U. S. A. 1967, 58, 719.

(10) Wozniak, A. K.; Schröder, G. F.; Grubmüller, H.; Seidel, C. A. M.; Oesterhelt, F. Proc. Natl. Acad. Sci. U. S. A. 2008, 105, 18337.

(11) Dodd, D. W.; Hudson, R. H. E. Mini-Rev. Org. Chem. 2009, 6, 378.

(12) Sinkeldam, R. W.; Greco, N. J.; Tor, Y. Chem. Rev. 2010, 110, 2579.

(13) Wilhelmsson, L. M. Q. Rev. Biophys. 2010, 43, 159.

(14) Hurley, D. J.; Tor, Y. J. Am. Chem. Soc. 2002, 124, 13231.

(15) Lewis, F. D.; Zhang, L. G.; Liu, X. Y.; Zuo, X. B.; Tiede, D. M.; Long, H.; Schatz, G. C. J. Am. Chem. Soc. 2005, 127, 14445.

(16) Börjesson, K.; Preus, S.; El-Sagheer, A. H.; Brown, T.; Albinsson, B.; Wilhelmsson, L. M. J. Am. Chem. Soc. 2009, 131, 4288.

(17) Mata, G.; Schmidt, O. P.; Luedtke, N. W. Chem. Commun. 2016, 52, 4718.

(18) Wilson, J. N.; Kool, E. T. Org. Biomol. Chem. 2006, 4, 4265.

(19) Sandin, P.; Börjesson, K.; Li, H.; Mårtensson, J.; Brown, T.; Wilhelmsson, L. M.; Albinsson, B. Nucleic Acids Res. 2008, 36, 157.

(20) Sandin, P.; Wilhelmsson, L. M.; Lincoln, P.; Powers, V. E. C.; Brown, T.; Albinsson, B. Nucleic Acids Res. 2005, 33, 5019.

(21) Preus, S.; Kilså, K.; Miannay, F. A.; Albinsson, B.; Wilhelmsson, L. M. Nucleic Acids Res. 2013, 41 (1), e18.

(22) Dumat, B.; Bood, M.; Wranne, M. S.; Lawson, C. P.; Larsen, A. F.; Preus, S.; Streling, J.; Gradén, H.; Wellner, E.; Grøtli, M.; Wilhelmsson, L. M. Chem. - Eur. J. 2015, 21, 4039.

(23) Dierckx, A.; Miannay, F. A.; Gaied, N.; Preus, S.; Björck, M.; Brown, T.; Wilhelmsson, L. M. Chem. - Eur. J. 2012, 18, 5987.

(24) Benneche, T.; Gundersen, L.-L.; Undheim, K. Acta Chem. Scand. 1988, $42 b, 384$.

(25) Magnin, G. C.; Dauvergne, J.; Burger, A.; Biellmann, J.-F. Tetrahedron Lett. 1996, 37, 7833.

(26) Lang, P.; Magnin, G.; Mathis, G.; Burger, A.; Biellmann, J.-F. J. Org. Chem. 2000, 65, 7825.

(27) Foller Larsen, A.; Dumat, B.; Wranne, M. S.; Lawson, C. P.; Preus, S.; Bood, M.; Gradén, H.; Wilhelmsson, L. M.; Grøtli, M. Sci. Rep. 2015, 5, 12653.

(28) Hoffer, M. Chem. Ber. 1960, 93, 2777.

(29) Kypr, J.; Kejnovská, I.; Renciuk, D.; Vorlicková, M. Nucleic Acids Res. 2009, 37, 1713.

(30) Engman, K. C.; Sandin, P.; Osborne, S.; Brown, T.; Billeter, M.; Lincoln, P.; Nordén, B.; Albinsson, B.; Wilhelmsson, L. M. Nucleic Acids Res. 2004, 32, 5087.

(31) Johnson, N. P.; Baase, W. A.; Von Hippel, P. H. Proc. Natl. Acad. Sci. U. S. A. 2004, 101, 3426.

(32) Xu, D.; Evans, K. O.; Nordlund, T. M. Biochemistry 1994, 33, 9592.

(33) Hawkins, M. E.; Pfleiderer, W.; Balis, F. M.; Porter, D.; Knutson, J. R. Anal. Biochem. 1997, 244, 86.

(34) Hawkins, M. E. Cell Biochem. Biophys. 2001, 34, 257.

(35) Gao, J. M.; Liu, H. B.; Kool, E. T. J. Am. Chem. Soc. 2004, 126, 11826.

(36) Mizrahi, R. A.; Shin, D. W.; Sinkeldam, R. W.; Phelps, K. J.; Fin, A.; Tantillo, D. J.; Tor, Y.; Beal, P. A. Angew. Chem., Int. Ed. 2015, 54, 8713.

(37) Rovira, A. R.; Fin, A.; Tor, Y. J. Am. Chem. Soc. 2015, 137, 14602.

(38) Jones, A. C.; Neely, R. K. Q. Rev. Biophys. 2015, 48, 244.

(39) Onidas, D.; Markovitsi, D.; Marguet, S.; Sharonov, A.; Gustavsson, T. J. Phys. Chem. B 2002, 106, 11367.

(40) Hawkins, M. E.; Pfleiderer, W.; Jungmann, O.; Balis, F. M. Anal. Biochem. 2001, 298, 231.

(41) Holmén, A.; Nordén, B.; Albinsson, B. J. Am. Chem. Soc. 1997, $119,3114$.

(42) Wojciechowski, F.; Hudson, R. H. E. J. Am. Chem. Soc. 2008, 130,12574

(43) Shin, D.; Sinkeldam, R. W.; Tor, Y. J. Am. Chem. Soc. 2011, 133, 14912. 
(44) Da Costa, C. P.; Fedor, M. J.; Scott, L. G. J. Am. Chem. Soc.

2007, 129, 3426.

(45) Ward, D. C.; Reich, E.; Stryer, L. J. Biol. Chem. 1969, 244, 1228.

(46) Berry, D. A.; Jung, K. Y.; Wise, D. S.; Sercel, A. D.; Pearson, W. H.; Mackie, H.; Randolph, J. B.; Somers, R. L. Tetrahedron Lett. 2004, 45, 2457.

(47) Somsen, O. J. G.; Hoek, V. A.; Amerongen, V. H. Chem. Phys. Lett. 2005, 402, 61.

(48) Dierckx, A.; Dinér, P.; El-Sagheer, A. H.; Kumar, J. D.; Brown, T.; Grøtli, M.; Wilhelmsson, L. M. Nucleic Acids Res. 2011, 39, 4513.

(49) Okamoto, A.; Saito, Y.; Saito, I. J. Photochem. Photobiol., C 2005, 6, 108.

(50) Seidel, C. A. M.; Schulz, A.; Sauer, M. H. M. J. Phys. Chem. 1996, 100, 5541.

(51) Manoharan, M.; Tivel, K. L.; Zhao, M.; Nafisi, K.; Netzel, T. L. J. Phys. Chem. 1995, 99, 17461.

(52) Albert, A.; Taguchi, H. J. Chem. Soc., Perkin Trans. 2 1973, 1101.

(53) Sholokh, M.; Sharma, R.; Shin, D.; Das, R.; Zaporozhets, O. A.;

Tor, Y.; Mély, Y. J. Am. Chem. Soc. 2015, 137, 3185.

(54) Stanley, R. J.; Hou, Z. J.; Yang, A. P.; Hawkins, M. E. J. Phys. Chem. B 2005, 109, 3690.

(55) Gaied, N. B.; Glasser, N.; Ramalanjaona, N.; Beltz, H.; Wolff, P.; Marquet, R.; Burger, A.; Mély, Y. Nucleic Acids Res. 2005, 33, 1031.

(56) Van Aerschot, A. A.; Mamos, P.; Weyns, N. J.; Ikeda, S.; De Clercq, E.; Herdewijn, P. A. J. Med. Chem. 1993, 36, 2938.

(57) Liu, C.; Martin, C. T. J. Mol. Biol. 2001, 308, 465.

(58) Sanabia, J. E.; Goldner, L. S.; Lacaze, P. A.; Hawkins, M. E. J. Phys. Chem. B 2004, 108, 15293.

(59) Wilhelmsson, L. M.; Sandin, P.; Holmen, A.; Albinsson, B.; Lincoln, P.; Norden, B. J. Phys. Chem. B 2003, 107, 9094.

(60) Mohammed, O. F.; Vauthey, E. J. Phys. Chem. A 2008, 112, 3823.

(61) Preus, S.; Kilså, K.; Wilhelmsson, L. M.; Albinsson, B. Phys. Chem. Chem. Phys. 2010, 12, 8881.

(62) Preus, S.; Börjesson, K.; Kilså, K.; Albinsson, B.; Wilhelmsson, L. M. J. Phys. Chem. B 2010, 114, 1050.

(63) Kopka, M. L.; Yoon, C.; Goodsell, D.; Pjura, P.; Dickerson, R. E. Proc. Natl. Acad. Sci. U. S. A. 1985, 82, 1376.

(64) Lipfert, J.; Klijnhout, S.; Dekker, N. H. Nucleic Acids Res. 2010, $38,7122$.

(65) Premvardhan, L.; Maurizot, J. C. Eur. Biophys. J. 2010, 39, 781.

(66) Triebel, H.; Bär, H.; Geuther, R.; Burckhardt, G. Prog. Coll. Polym. Sci. S. 1995, 99, 45.

(67) Snounou, G.; Malcolm, A. D. B. J. Mol. Biol. 1983, 167, 211.

(68) Rettig, M.; Germann, M. W.; Wang, S.; Wilson, W. D. ChemBioChem 2013, 14, 323.

(69) Dattagupta, N.; Hogan, M.; Crothers, D. M. Biochemistry 1980, 19, 5998. 